\title{
Case Study of Healthcare Organization Improvement with Lean Concept
}

\author{
Majed ALKHER, Milan RADOŠEVIĆ, Ivan BEKER, Velibor ČABARKAPA, Danijela TOLJAGA-NIKOLIĆ, \\ Marko CARIĆ, Slobodan MORAČA
}

\begin{abstract}
The goal of each company today is to improve business and increase profit through the reorganization and simplification of its processes, decrease of costs and resources utilization etc. Improving the business is usually implemented through different techniques and methodologies that have been developed. One of the ways to improve service processes, and health system processes also, is the implementation of the lean concept. This study shows benefits from using Lean tools value stream mapping (VSM) and simulations to simplify the laboratory work process. Using the VSM and simulation in department of clinical biochemistry authors showed significant improvement of the clinical processes such as eliminating non-value added times (NVAT) by minimum 30 working days/year, increasing number of laboratories analyses by approximately 80.000 analyses/year, eliminating unnecessary movement of 39,000 - 52,000 meters/year for samples and 78,000 - 104,000 meters/year for stuff and decreasing patient waiting times from average 70 to $20 \mathrm{~min} /$ patient.
\end{abstract}

Keywords: healthcare organization; lean; process improvement; simulation; VSM

\section{INTRODUCTION}

The contemporary business of both, service and manufacturing companies, is becoming more and more challenging. Some authors emphasize that, due to the constant market turbulence, companies that are based on the old business principles can have significant problems with the survival on the market [1]. A very turbulent market, a dynamic environment, and unpredicted business conditions as well as many other factors that directly or indirectly affect the business itself, force managers to enable their processes to respond to the market demands in a very short period of time. It is very common that the processes are not set up on the appropriate bases, or that they are efficient and effective, but they are not flexible enough. Therefore, they cannot be adapted to the sudden changes and demands of consumers in a timely manner. Several authors emphasize the need for changes in the way of doing business, primarily in the area of modification and integration of business processes at all levels [2]. One of the strategic approaches in creating very flexible, efficient and effective production and service systems can be applied with the help of the lean concept. The lean concept represents an approach to such a process design that ensures the highest degree of flexibility, efficiency, and effectiveness, with emphasis on customer satisfaction as an imperative, and the employees as the mainholders of the process (see [3]). "Profit" that can be realized with the implementation of the lean concept, whether the process is designed as a new one or is a reorganization of an already existing system, is a subject of numerous researches [4-8].

This work is divided into two parts. The first part presents a literary overview of the researches that deal with the implementation of the lean concept in healthcare institutions as well as in clinical laboratories, with a description of the lean concept as a "philosophy" of process improvement and the lean tool for mapping of the process. Mapping of the process is supported by the simulation of the system, which has been done with the help of mapping tools. The research was conducted in the clinical laboratory for biochemistry and in the department for receiving and distribution of samples in one state clinical center.
A review of the available literature revealed fewer researches that were dealing with the implementation of the lean concept in the processes of clinical laboratories. The aim of this paper is to deepen the research in the field of implementation of the lean concept in clinical laboratories. For the purposes of the work, a statistical analysis of the data from the survey was performed by SPSS software package. Spearman's correlation was used to determine the correlation between the measured real time of the patients and their subjective sense of time for a blood draw, while the VSM lean tool was applied for the mapping of the process, and the FlexSim HC software package was used for the simulation of the system itself.

Clinical laboratories are a very important part of each health institution, and any improvement in this process certainly contributes to their better work. The quality and speed of the work of clinical laboratories ensure the timely adoption of appropriate diagnoses for the treatment of patients. The significance of this paper lies in the extension of knowledge in the field of implementation of the lean concept supported by simulation in healthcare institutions, especially in clinical laboratories, with an emphasis on the benefits that can be achieved.

\section{THEORETICAL BACKGROUND}

The term "lean" first appeared in the book "The machine that changed the world" [9] where the authors showed differences between the Japanese production methods and traditional mass production from the West. The book discussed approaches which the Japanese automobile industry used to take the precedence over the American automotive industry [10]. Authors Womack et al. have defined this approach as lean, under the definition that lean: "provides a way to do more work with less human effort, less equipment, less time, and less space while coming closer to providing customers with exactly what they want" [3].

For the purpose of the research authors in this paper used one of the "most popular" lean tools, the VSM - Value stream mapping. The worldwide usage of this tool started after the publication of the book of the authors Rother \& 
Shook entitled "Learning to See" [11]. Rother \& Shook presented mapping process as "wherever there is a product for a customer, there is a value stream". According to the same authors, value stream represents the sum of all the activities within each process necessary to produce a particular product [12]. These actions consider the flow of both information and materials within the overall supply chain. The ultimate goal of VSM is to identify all types of waste in the value stream and to take steps to try to eliminate these wastes (for more see $[11,13]$ ). The review of the literature ([13-17]) leads to the conclusion that there exists a consensus about the phases of the implementation of VSM lean tool. Those phases can be presented as:

1. Initiating changes,

2. VSM current state map,

3. VSM future state map,

4. (Simulation) - optional, not obligatory,

5. Implementation.

An optional step in applying VSM tool is a simulation of the operation of a new system, which is used more and more today (see [18-21]. Simulation platforms are software tools that ensure that real systems are "converted" into an electronic form no matter how complex the system was [2]. The literature points to numerous benefits that can be achieved with the implementation of simulations (see [2224]). Some authors state that the significance of the simulation is primarily reflected in the possibility of collecting data from virtual system simulations with the help of various inputs in order to obtain the best possible output, and based on the detailed outputs, it is possible to make the most favorable decisions that the system will choose and implement [2].

Today's software packages enable us to simulate the results of a new system and to reach a conclusion about whether a new draft system is justified or not before the final step of implementation of the final solution. VSM tool is a very effective tool that allows us to get information on wastes (muda) that occur within the system and to eliminate these wastes easier and as soon as possible [25].

The application of the lean concept is not just a trend in the manufacturing industry; it is increasingly introduced in the service industry, too. One of the representatives of service industries is certainly a health system. A review of the available literature shows that there is not a great number of authors who are dealing with the implementation of the lean concept in clinical laboratories supported by the simulation application, and that it is a trend that is rising (see [26-29]). According to author Majed et al. implementation of the lean concept is not related just to the improvement of a medical institution as a whole, but to the implementation of the lean concepts in each subsystem of a medical institution [30]. Authors Plytiuc et al. emphasize that "subsystems" of a medical institution obtain clinical laboratories, nursing, primary care, perioperative service, emergency department, anatomic pathology, etc. [31]. The same authors presented a literature review of the lean in the healthcare sector with the aim of pointing out the poor relations of research and the area that is rich for further research. On the other hand, the authors Alkher et al. created a literature overview of the specific lean tools that was implemented by some researchers in hospitals and clinical laboratories procedures, as well as the effects of those implementations [30].

\section{METHODOLOGY}

The research was conducted in the clinical center, at the department for clinical biochemistry, which performs more than a million different analyses per year, and which serves approximately $100.000-110.000$ patients per year. The research approach was conducted in a few phases. In the starting phase of the research, the questionnaire of the opinion of the patients was used in order to explore the subjective feelings and expected subjective times. 312 patients were questioned, while the blood draw process was recorded for 140 patients. The idea was to compare the subjective predicted times with the real measured times for determining whether the subjectively expected time is the same/or is similar to real-time, and on that basis, the simulation results are predicted.

In addition to interviewing patients, interviews were also conducted with employees. The aim of these conversations with employees was to explore the overall picture of the process.

Statistical analysis was performed by SPSS software package. Spearman's correlation was used to determine the correlation between the measured real time of the patients and their subjective sense of time for a blood draw. Spearman's rank correlation coefficient is a nonparametric (distribution-free) rank statistic as a measure of the strength of an association between two variables [32]. After collecting patient and employee attitudes, as well as system analysis, a display of the current and new state of the system was made with the help of the lean VSM mapping tool. Processes shown by using VSM were simulated with the FlexSim HC software package and the results of the research are shown in more detail below.

\section{RESULTS}

According to the results of questionaries' in survey for patients (see Tab. 1), the mean value of the duration of the blood draw process - subjective times (presented as opinion of the patients who were questioned) is around 73 minutes $(M=73,14 ; S D=45,80 ; M A X=240 ; M I N=5 ; N$ $=140$ ), while the mean value of the duration of the blood draw process - objective times (presented as the measured times by researcher) is 60,56 minutes $(M=60,56 ; S D=$ $33,41 ; M A X=173 ; M I N=12 ; N=140)$. There has been detected a strong positive statistically significant correlation between the mean value of the duration of the blood draw process - objective times and subjective time ( $r h o=0,837 ; p<0,001 ; N=140$ ). Based on the high positive statistically significant correlation between the duration of the blood draw process objective times and subjective times it is possible to implement a simulation of the process.

In parallel with patient testing, time measurement and the determination of statistically significant positive correlations, the overall analysis of the work of the laboratory for clinical biochemistry and the laboratory for the reception and distribution of materials was carried out (both employees and patients were included), which is shown in detail with the application of VSM (Fig. 1). 


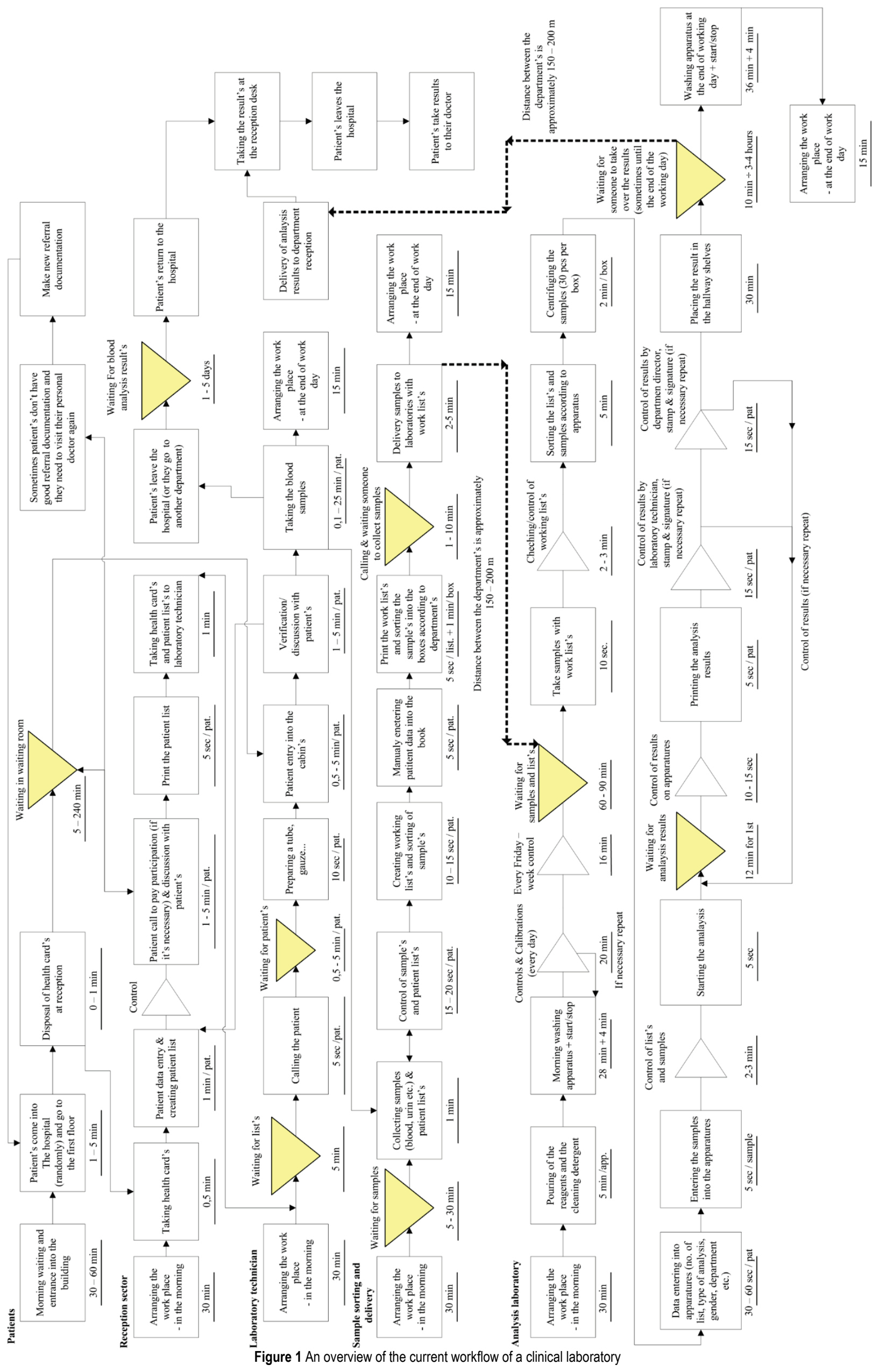




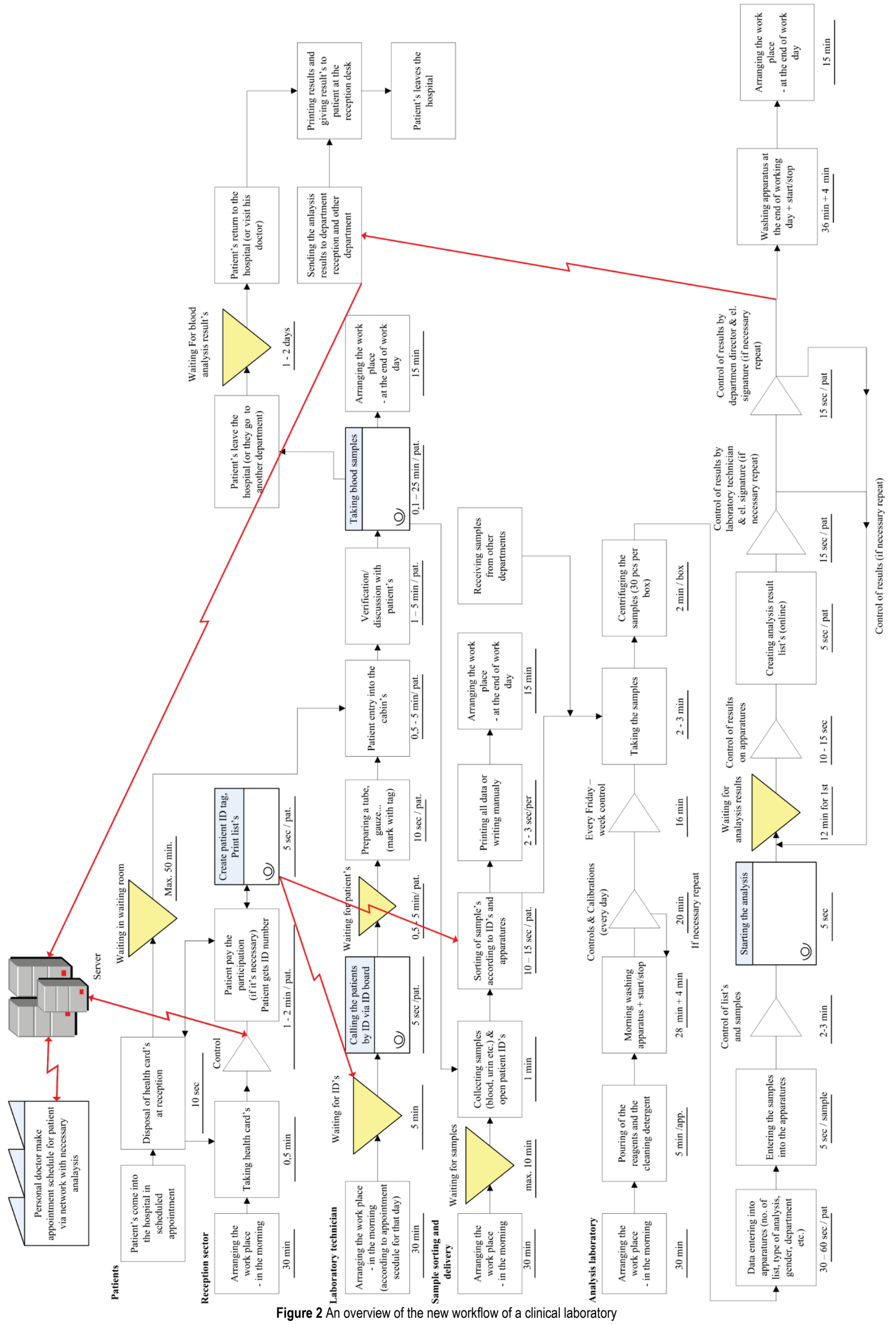




\begin{tabular}{|c|c|c|c|c|c|}
\hline & & Mean & $S D$ & $\begin{array}{l}\text { The duration of the blood } \\
\text { draw process - subjective } \\
\text { times }\end{array}$ & $\begin{array}{l}\text { The duration of the blood } \\
\text { draw process - objective } \\
\text { times }\end{array}$ \\
\hline \multirow{2}{*}{$\begin{array}{l}\text { The duration of the blood draw process - } \\
\text { subjective times }\end{array}$} & rho & \multirow[t]{2}{*}{73,1357} & \multirow[t]{2}{*}{45,79941} & 1,000 &, $837^{* *}$ \\
\hline & Sig. (2-tailed) & & & &, 000 \\
\hline \multirow{2}{*}{$\begin{array}{l}\text { The duration of the blood draw process - } \\
\text { objective times }\end{array}$} & rho & \multirow[t]{2}{*}{60,5643} & \multirow[t]{2}{*}{33,41417} &, $837^{* *}$ & 1,000 \\
\hline & Sig. (2-tailed) & & &, 000 & \\
\hline
\end{tabular}

During research, in the current system, we found large crowds in the receiving department in the morning. One of the reasons is certainly the time for collecting health cards that last for two hours $(7-9$ am) and the lack of a scheduling system for patients. Given that $350-400$ patients are served on a daily basis, due to the admission of health cards for a period of two hours, all patients must come in the specified period if they want to be served. Current hospital capacities are not designed to accommodate so many patients in such a short period of time and also there is not enough seating space in the waiting room. As emphasized earlier, it was noticed that all the rooms are not operating at the same time and that samples are not taken in all rooms. The analysis of the system also detected other problems that are primarily reflected in the separation of the sampling and distribution departments and the laboratory for analysis (150 - 200 meters), which makes the unnecessary movement of samples and patients, lack of information system, a large crowd in the waiting room, waiting for analysis results, etc. In order to improve the system by eliminating all of these problems, a detailed analysis of the new system by using VSM (Fig. 2) is given, with an emphasis on the benefits obtained by system simulation by using the FlexSim HC software package.

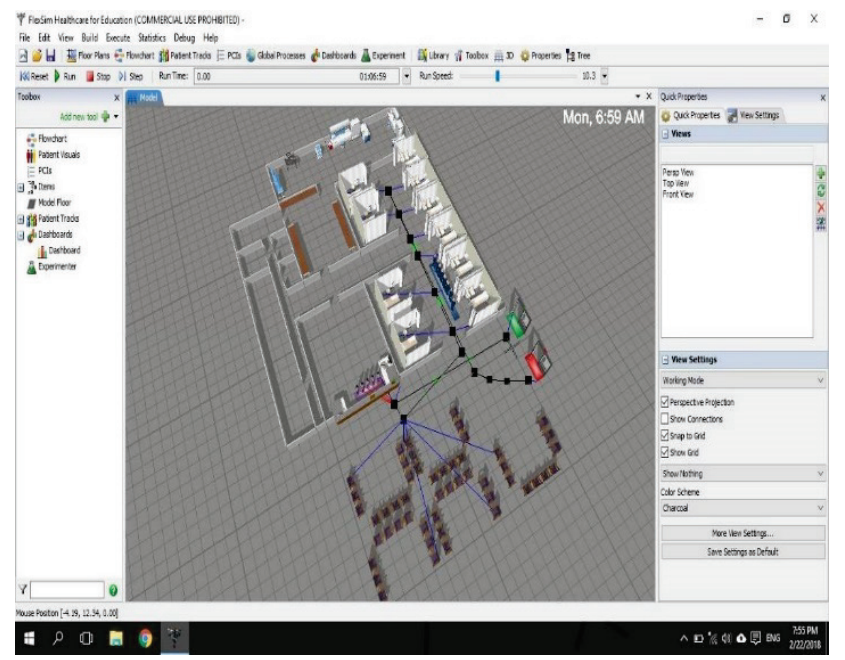

Figure 3 Simulation of the system inFlexSim

The FlexSim HC software package is intended for the concrete application of simulation processes in healthcare institutions that, in addition to the results of the simulation, also provide a real visualization of the process and the movement of patients and employees in the process. The basic changes in the new process are certainly reflected in the new layout of the department for reception and distribution of materials to which the clinical biochemistry department was attached (Fig. 3).
Such spatial structure ensures the elimination of the movement of samples between the departments (in the amount of 150 - 200 meters between buildings). This layout will completely ensure elimination of the waiting time for the samples for 60 - 90 minutes per day, saving time from minimum 30 working days per year and sometimes waiting for the apparatus functionality of 12 minutes due to lack of samples. Since the daily level of analysis in the biochemical laboratory is acc. 2.700 analysis/day, the merger of the departments would provide more analyses of approximately 80.000 analysis per year and will result in time-saving, too. In addition to the increase of the efficiency of the laboratory, it would eliminate the movement of samples in the amount of $39,000-52,000$ meters / year, as well as the movement of employees who must cross the path to take samples from the reception and distribution department and submit it to the department for clinical biochemistry from 78,000 104,000 meters / year. It is also important to note that due to the loss of the time in the amount of at least one month per year, the savings on the salaries of employees would save a significant amount of the money annually, which could be invested in improving the process itself or in hiring new people. In the new system, the receipt of cards would not be performed in the morning from 7 to 9 hours, but it would be distributed according to scheduled appointments, that is, the system will be set up so that patients came in line with scheduled appointments, which would ensure the maintenance of approximately 400 patients per day. In addition to the new arrangement of the layout system and the scheduling system, other improvements have been introduced, such as job changes, a number of sample collection rooms, etc.

The new system is set up so that the number of workrooms is expanded from 8 to 10 rooms, while the number of employees at the counter is reduced by two employees, from the current 7 to 5 employees. Since the time spent in the sampling rooms is the longest working phase, by introducing only two study rooms, the process is accelerated for almost 20 patients per hour, representing almost 60 patients in 3 hours, an increase of $15 \%$ on an observed sample of 400 patients per day.

Based on all of the above facts, it was concluded that new system is the most optimal solution that, with very little investment in resources, using existing resources (employees), ensures the best use of resources, it equips patient waiting, ensures continuous flow of the process, provides approximately uniform patient groups according to scheduling terms, etc.

\section{CONCLUSION}

The application of the lean concept in healthcare institutions has become the subject of recent researches. However, by reviewing available literature, it is not possible to notice a significant number of studies 
specifically focused on research on the implementation of lean concepts in clinical laboratories such as laboratories for clinical biochemistry. Clinical biochemistry laboratories are very important subsystems of each healthcare institution because quality work of the laboratory for clinical biochemistry provides data that are the basis for medical diagnosis and patients' treatments. In the paper, the implementation of the lean concept was applied with the application of a lean tool for mapping the VSM process. The process is mapped based on a detailed system analysis with the aim of identifying all sites that do not provide a continuous process. When analyzing the system, through surveys, as well as through interviews, data were collected from both, patients and employees, in order to obtain a comprehensive picture of the process. After creating a new process, based on the lean principles, a simulation of the system with different parameters was performed in order to obtain the most optimized process that provides the fastest workflow, eliminating non-value added times (NVAT), providing minimum supplies, shortening the time of analysis of results, waiting times for patients, etc.

This study finds that by integrating the VSM lean tool and simulation, it is possible to obtain very significant improvements in the implementation of the lean concept in clinical laboratories. The advances are reflected in the elimination of unnecessary movement of the samples between the receiving and distribution departments and clinical biochemistry departments and the amount of 39,000 - 52,000 meters/year, i.e. the unnecessary movement of employees in the amount of 78,000 - 104,000 meters/year. Waiting for the submission of samples between the departments was eliminated, which was between 30 - 90 minutes on a daily basis and at the annual level of almost 30 working days. At the present system the daily level of the analysis is about 2,700 analyses, and by eliminating time for waiting for the samples, conditions are provided for more analysis in the amount of approximately 80,000 analyses/year. Delivery of the results is no longer performed in a manual way, but all the results of the analyses between the departments are submitted electronically, which, in addition to reducing time, also reduces the consumption of resources (printing paper, toner, etc.). The introduction of the patient scheduling system provides the basis for the creation of minimum stocks for work resources because based on the number of scheduled patients it is possible to make a minimum stock budget, timely planning and procurement of resources for work. The reorganization of jobs provided an increase in patient attendance in sampling rooms by $15 \%$ on a sample of 400 patients per day, and the total process time was also improved by $15 \%$.

It is very important to mention the limitations that the authors have faced during the research, which is primarily reflected in the dissatisfaction of the patients with the process itself, because of the large crowds, due to which a significant number of patients refused to participate in the survey. Employee dissatisfaction with the process of work as well as interpersonal relations in relation to patientemployee and employee-employee were also noticed. Despite the constraints listed, all participants supported the changes that began after the research, ranging from the management of the laboratory to the employees, which represent the initial capsule for the successful implementation of the lean concept. The future focus of the authors is the study of the impact of the implementation of the lean concept in clinical laboratories on increasing patient and employee satisfaction.

\section{REFERENCES}

[1] Veza, I., Mladineo, M., \& Gjeldum, N. (2016). Selection of the basic lean tools for development of Croatian model of innovative smart enterprise. Tehnički vjesnik, 23(5), 13171324. https://doi.org/10.17559/TV-20160202120909

[2] Božičković, R., Radosevic, M., Ćosić, I., Soković, M., \& Rikalović, A. (2012). Integration of simulation and lean tools in effective production systems-Case study. Strojniški vestnik-Journal of Mechanical Engineering, 58(11), 642652. https://doi.org/10.5545/sv-jme.2012.687

[3] Womack, J. P. \& Jones, D. T. (1997). Lean thinking banish waste and create wealth in your corporation. Journal of the Operational Research Society, 48(11), 1148-1148. https://doi.org/10.1057/palgrave.jors.2600967

[4] Stone, K. B. (2012). Four decades of lean: a systematic literature review. International Journal of Lean Six Sigma, 3(2), 112-132. https://doi.org/10.1108/20401461211243702

[5] Poksinska, B. (2010). The current state of Lean implementation in health care: literature review. Quality Management in Healthcare, 19(4), 319-329. https://doi.org/10.1097/QMH.0b013e3181fa07bb

[6] Bhamu, J. \& Singh Sangwan, K. (2014). Lean manufacturing: literature review and research issues. International Journal of Operations \& Production Management, 34(7), 876-940. https://doi.org/10.1108/ijopm-08-2012-0315

[7] Królczyk, G., Legutko, S., Królczyk, J., \& Tama, E. (2014). Materials flow analysis in the production process-case study. Applied Mechanics and Materials, Trans Tech Publications, 474, 97-102. https://doi.org/10.4028/www.scientific.net/AMM.474.97

[8] Vorkapić, M., Radovanović, F., Ćoćkalo, D., \& Đorđević, D. (2017). Applicability of the lean concept to the management of small-scale manufacturing enterprises in Serbia. Tehnički vjesnik, 24(6), 1929-1934. https://doi.org/10.17559/TV-20150807194942

[9] Womack, J. P., Jones, D. T., \& Roos, D. (1990). Machine that changed the world. Simon and Schuster.

[10] Melton, T. (2005). The benefits of lean manufacturing: what lean thinking has to offer the process industries. Chemical engineering research and design, 83(6), 662-673. https://doi.org/10.1205/cherd.04351

[11] Rother, M. \& Shook, J. (1999). Learning to see. Lean Enterprise Institute, Cambridge, MA.

[12] Rother, M. \& Shook, J. (2003). Learning to see: value stream mapping to add value and eliminate muda. Lean Enterprise Institute.

[13] Abdulmalek, F. A. \& Rajgopal, J. (2007). Analyzing the benefits of lean manufacturing and value stream mapping via simulation: A process sector case study. International Journal of production economics, 107(1), 223-236. https://doi.org/10.1016/j.ijpe.2006.09.009

[14] Tyagi, S., Choudhary, A., Cai, X., \& Yang, K. (2015). Value stream mapping to reduce the lead-time of a product development process. International Journal of Production Economics, 160, 202-212 https://doi.org/10.1016/j.jpe.2014.11.002

[15] Morlock, F. \& Meier, H. (2015). Service value stream mapping in industrial product-service system performance management. Procedia CIRP, 30, 457-461. https://doi.org/10.1016/j.procir.2015.02.128 
[16] Rohac, T. \& Januska, M. (2015). Value stream mapping demonstration on real case study. Procedia Engineering, 100, 520-529. https://doi.org/10.1016/j.proeng.2015.01.399

[17] Venkataraman, K., Ramnath, B. V., Kumar, V. M., \& Elanchezhian, C. (2014). Application of value stream mapping for reduction of cycle time in a machining process. Procedia Materials Science, 6, 1187-1196. https://doi.org/10.1016/j.mspro.2014.07.192

[18] Gjeldum, N., Veža, I., \& Bilić, B. (2011). Simulation of production process reorganized with Value Stream Mapping. Tehnički vjesnik, 18(3), 341-347. Retrieved from https://hrcak.srce.hr/71813.

[19] Lian, Y. H. \& Van Landeghem, H. (2002, October). An application of simulation and value stream mapping in lean manufacturing. In Proceedings $14^{\text {th }}$ European Simulation Symposium (pp. 1-8). c) SCS Europe BVBA.

[20] Lian, Y. H. \& Van Landeghem, H. (2007). Analysing the effects of Lean manufacturing using a value stream mapping-based simulation generator. International Journal of Production Research, 45(13), 3037-3058. https://doi.org/10.1080/00207540600791590

[21] Solding, P. \& Gullander, P. (2009, December). Concepts for simulation based value stream mapping. Proceedings of Winter Simulation Conference (WSC), IEEE Computer Society, 2231-2237. https://doi.org/10.1109/WSC.2009.5429185

[22] De Jong, H. (2002). Modeling and simulation of genetic regulatory systems: a literature review. Journal of computational biology, 9(1), 67-103. https://doi.org/10.1089/10665270252833208

[23] Tumay, K. (1995, December). Business process simulation. Proceedings of the $28^{\text {th }}$ Conference on Winter Simulation (WSC), IEEE Computer Society, 93-98. https://doi.org/10.1109/WSC.1995.478705

[24] Fermeglia, M. (2008). Role of Process Simulation in Extraction Technologies for Medicinal and Aromatic Plants, 55.

[25] Xia, W. \& Sun, J. (2013). Simulation guided value stream mapping and lean improvement: A case study of a tubular machining facility. Journal of Industrial Engineering and Management, 6(2), 456. https://doi.org/10.3926/jiem.532

[26] Ellis, D., Crofts, J. F., Hunt, L. P., Read, M., Fox, R., \& James, M. (2008). Hospital, simulation center, and teamwork training for eclampsia management: a randomized controlled trial. Obstetrics \& Gynecology, 111(3), 723-731. https://doi.org/10.1097/AOG.0b013e3181637a82

[27] Lowery, J. C. (1996, November). Design of hospital admissions scheduling system using simulation. In Proceedings of the $28^{\text {th }}$ conference on Winter simulation, IEEE Computer Society, 1199-1204. https://doi.org/10.1145/256562.256932

[28] Gunal, M. M. (2012). A guide for building hospital simulation models. Health Systems, 1(1), 17-25. https://doi.org/10.1057/hs.2012.8

[29] Arora, S., Cox, C., Davies, S., Kassab, E., Mahoney, P., Sharma, E., \& Sevdalis, N. (2014). Towards the next frontier for simulation-based training: full-hospital simulation across the entire patient pathway. Annals of surgery, 260(2), 252258. https://doi.org/10.1097/sla.0000000000000305

[30] Alkher, M., Beker, I., Cabarkapa, V., \& Sevic, D. (2017) Most used lean tools in hospitals and clinical laboratories, XVII International Scientific Conference on Industrial Systems, Novi Sad, Serbia (pp. 278-283)

[31] Plytiuk, C. F., Gouvea da Costa, S. E., \& Pinheiro de Lima, E. (2013). Lean in healthcare: a systematic literature review and social network analysis. In POMS $25^{\text {th }}$ Annual Conference, Atlanta, GA, USA, May (pp. 9-12).

[32] Hauke, J. \& Kossowski, T. (2011). Comparison of values of Pearson's and Spearman's correlation coefficients on the same sets of data. Quaestiones Geographicae, 30(2), 87-93. https://doi.org/10.2478/v10117-011-0021-1

\section{Contact information:}

Majed ALKHER, MSc

University of Novi Sad

Faculty of Technical Sciences,

Trg Dositeja Obradovića 6, 21000 Novi Sad, Serbia

majed1215@yahoo.com

Milan RADOŠEVIĆ, assist. prof. dr. sc.

(Corresponding author)

University Business Academy in Novi Sad,

Faculty of Economics and Engineering Management in Novi Sad,

Cvećarska 2, 21000 Novi Sad, Serbia

University of Novi Sad,

Faculty of Technical Sciences,

Trg Dositeja Obradovića 6, 21000 Novi Sad, Serbia

radosevic@uns.ac.rs

r.milan13@gmail.com

Ivan BEKER, prof. dr. sc.

University of Novi Sad,

Faculty of Technical Sciences,

Trg Dositeja Obradovića 6, 21000 Novi Sad, Serbia

beker@uns.ac.rs

Velibor ČABARKAPA, assoc. prof. dr. sc.

University of Novi Sad, Faculty of Medicine

Department of Clinical Biochemistry, Centre for Laboratory Medicine,

Clinical Centre of Vojvodina, Novi Sad, Serbia

veliborcabarkapa@gmail.com

Danije TOLJAGA-NIKOLIĆ, MSC

University of Belgrade, The Faculty of Organizational Sciences,

Jove llića 154, Beograd, Srbija

toljagad@fon.bg.ac.rs

Marko CARIĆ, prof. dr. sc.

University Business Academy in Novi Sad

Faculty of Law for Commerce and Judiciary in Novi Sad,

Cvećarska 2, 21000 Novi Sad, Serbia

macaric@yahoo.com

Slobodan MORAČA, assoc. prof. dr. sc.

University of Novi Sad,

Faculty of Technical Sciences,

Trg Dositeja Obradovića 6, 21000 Novi Sad, Serbia

moraca@uns.ac.rs 